\title{
Ultrasound biomicroscopy value in evaluation of restoration of ciliary muscles contractility after cataract extraction
}

This article was published in the following Dove Press journal:

Clinical Ophthalmology

4 May 2017

Number of times this article has been viewed

\author{
Ayser Abd El-Hameed \\ Fayed \\ Ophthalmology Department, Faculty \\ of Medicine, Banha University, Banha, \\ Egypt
}

Purpose: To assess the changes in the contractility of the ciliary muscle in eyes with presbyopia before and after phacoemulsification and intracapsular lens implantation using ultrasound biomicroscopy (UBM).

Patients and methods: This prospective study included 50 eyes of 30 consecutive subjects operated at the Department of Ophthalmology. Patients with any ocular disorder affecting visual acuity, corneal surface irregularities, had posterior capsular perforation or intensive postoperative corneal edema, or were $<35$ years of age, were excluded. A clear corneal phacoemulsification and posterior chamber intraocular lens were implanted. UBM was performed with and without instilling $2 \%$ pilocarpine. Ciliary body axial length (CBAXL), anterior chamber depth, and angle were measured before and 1 month after surgery.

Results: The CBAXL showed a greater contractile shortening $(P<0.5)$, with centripetal, contractile shift of ciliary muscle mass.

Conclusion: After phacoemulsification and intracapsular lens implantation, ultrasonic biomicroscopy showed significant centripetal movement of the ciliary body compared with that before surgery. This shows that a lenticular sclerotic component may influence both lens movement and the contractility of the ciliary muscle and is believed to be related to the presbyopia.

Keywords: ciliary body, presbyopia, accommodation, intraocular lens, pilocarpine

\section{Introduction}

Accommodation is the ability of the eye to modify the overall refractive power to deliver a sharp, image of near objects on the retina. ${ }^{1,2}$ The procedure is unquestionably administered by ciliary muscle contraction, the ciliary body moves and releases strain on the zonules that allow the lens equator to move away from the sclera, which allows the capsule to mold the young lens into a thicker, more convex, and dioptrically powerful form. ${ }^{3,4}$ Details concerning how ciliary muscle contraction influences zonular tension and the roles of the posterior zonules, iris, and vitreous body in accommodation remain unclear. ${ }^{1,5,6}$

During accommodation, the ciliary muscles contract and the ciliary body moves forward and inward, releasing tension on the zonules, which allows the lens equatorial diameter to decrease with an increase in the lens anteroposterior thickness. ${ }^{1,2}$ Magnetic resonance imaging has shown age-related decreases in the ciliary ring diameter in humans, which might affect accommodation and presbyopia. ${ }^{2}$

Ultrasound biomicroscopy (UBM) has shown greater displacement of the characteristics contour points of the ciliary body in younger volunteers than in older volunteers during accommodation. ${ }^{1,3}$ 
The goal of this in vivo study was to analyze the configurational changes of human ciliary muscles with accommodation before and after cataract surgery.

\section{Patients and methods}

Fifty eyes of 30 patients aged between 48 and 70 years with cataracts were included. Each eye underwent complete ophthalmic examination that included the best-corrected visual acuity, refraction, and indirect ophthalmoscopy. Subjects with eye disease affecting visual acuity, corneal surface irregularities, spherical refraction $>-2.0 \mathrm{D}$, posterior capsular perforation, or intensive postoperative corneal edema, or were aged $<35$ years, were excluded. A clear corneal phacoemulsification was performed, and posterior chamber intraocular lens (AcrySof SA60AT; Alcon Laboratories, Fort Worth, TX, USA) were implanted. UBM was
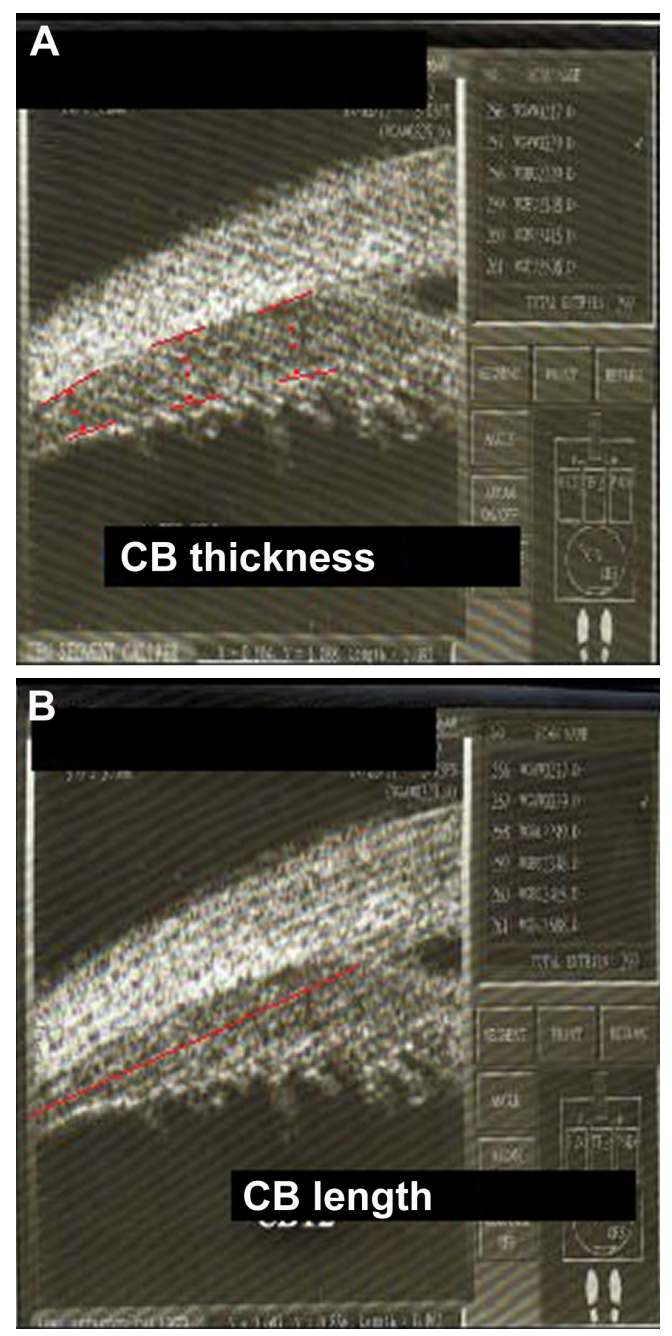

Figure I (A) Width measurements with caliper positioned perpendicular to the ciliary muscle-sclera and (B) visible ciliary muscle length from the scleral spur to the posterior tip of the ciliary muscle (red line).

Abbreviation: $\mathrm{CB}$, ciliary body. performed using an UBM 45 system (paradigm) $50 \mathrm{MHz}$ transducer probe that allowed for a $4-5 \mathrm{~mm}$ tissue penetration and $\sim 50 \mu \mathrm{m}$ resolution. The UBM examination was performed before and 30 minutes after instilling $2 \%$ pilocarpine hydrochloride to induce accommodative changes in the ciliary body. Scanning of the iridocorneal angle, including the ciliary body, was acquired at nasal and temporal quadrants. Image analysis was performed using software caliper to measure the following parameters: width measurements with caliper positioned perpendicular to the ciliary musclesclera boundary (Figure 1A); overall visible ciliary muscle length that was defined as the anteroposterior distance from the scleral spur to the posterior tip of the ciliary muscle (Figure 1B); ACD (anterior chamber depth) (Figure 2A and B); CBAXL (ciliary body axial length), which was defined as a line passing through the apex of the dome-shaped ciliary body and the center of ciliary body (Figure 3); SCPA (scleral ciliary process angle); three width measures were acquired, selected because of the known anterior shift of the ciliary
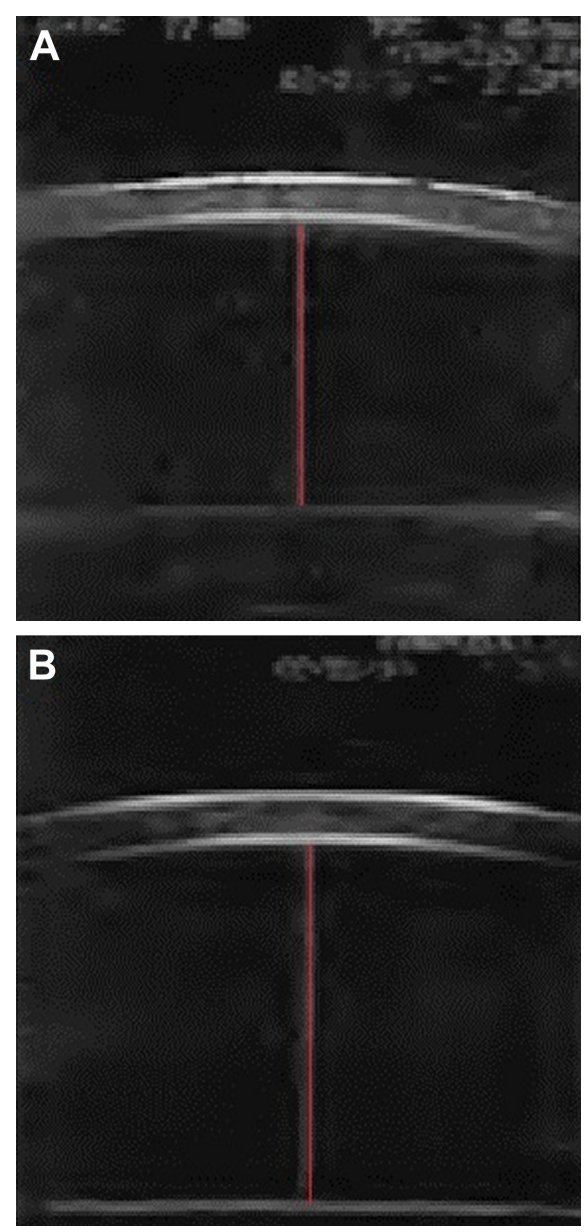

Figure 2 Anterior chamber depth (A) before and (B) after cataract surgery (red line extends from corneal endothelium to the anterior lens surface). 


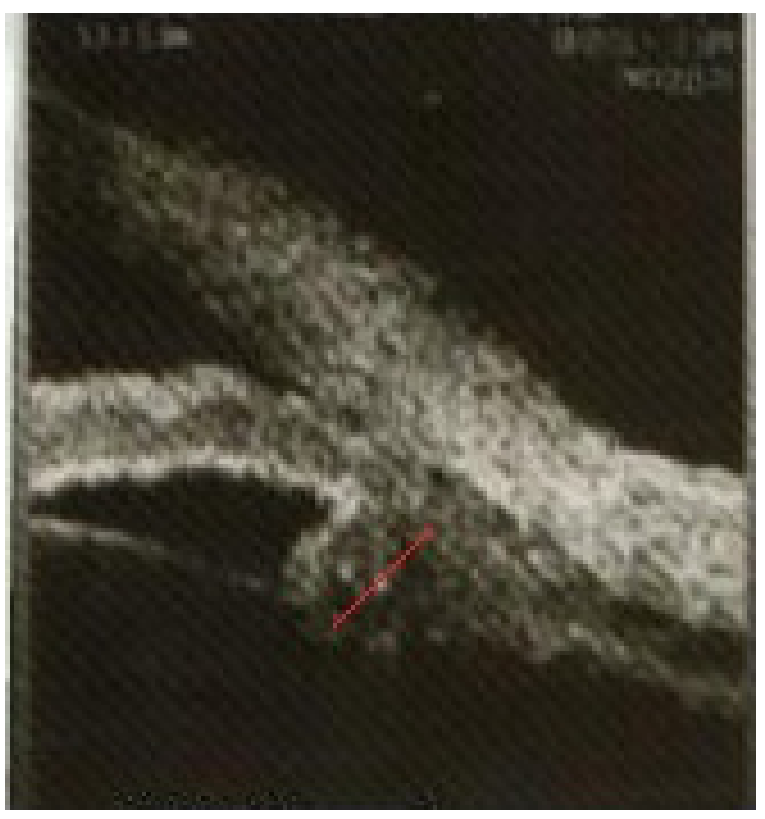

Figure 3 Ciliary body axial length, line passing through the apex of the dome-shaped ciliary body and the center of ciliary body (red line).

muscle with contraction. ${ }^{7,8}$ The parameters were measured using the methods reported by Pavlin et al..$^{9}$ The average of the parameters from the temporal quadrants was used in the analysis. Two months after the operation, the same parameters were measured again using UBM.

The participants provided written informed consent before examination. The consent form was approved by the ethics committee. The study was approved by the Review Boards and Ethics Committee of Banha University. This study adhered to the tenants of the Declaration of Helsinki.

\section{Results}

Mean objective accommodative changes after pilocarpine instillation are summarized in Table 1.

The UBM parameters from the temporal quadrants were used for statistical analysis. Considering ciliary muscle thickness, the CBAXL value with and without pilocarpine before cataract extraction was $1.699 \pm 0.150 \mathrm{~mm}$ and $1.685 \pm 0.180 \mathrm{~mm}$, respectively. Applying unpaired Student's $t$-test, there was no statistically significant difference in the mean CBAXL with and without pilocarpine before cataract extraction $(P=0.2)$. There was a statistically significant difference in CBAXL value with and without pilocarpine after cataract extraction $(P<0.5$; Figures 4 and 5$)$.

The central ACD decreased significantly after pilocarpine instillation was 3.533 and $2.968 \mathrm{~mm}$ before and after pilocarpine, respectively. Cataract surgery deepened the anterior chamber significantly, the ACD before and after pilocarpine instillation was 3.870 and $3.690 \mathrm{~mm}$, respectively, which contribute to the process of accommodation.

With regard to mean relaxed ciliary muscle, the overall length was $3.950 \pm 4.3 \mathrm{~mm}$. A statistically significant reduction in the overall ciliary muscle length during accommodation $(3.800 \mathrm{~mm})$ (after pilocarpine) was found $(P<0.05)$. The shortening with accommodation was significant after cataract extraction $(3.542 \mathrm{~mm})(P<0.001)$.

\section{Discussion}

Recent advances in ophthalmic imaging technology allow the ciliary muscle to be more easily visualized and imaged with sufficient resolution to detect accommodative changes. ${ }^{1,7,9-11}$

The amount of ciliary muscle contraction needed to produce a unit change in accommodation progressively increases with age. ${ }^{8}$ The precise role and functional relationships between the age-related changes in the ciliary muscles, zonular fibers, and lens are unclear due to the lack of dynamic measurement and difficulties in imaging the ocular element. ${ }^{8,10}$ In this study, we aimed to assess the changes in contractility of the ciliary muscle in eyes with presbyopia before and after phacoemulsification and intracapsular lens implantation using UBM. The CBAXL was used together with SCPA as an indicator of centripetal ciliary body movement during accommodation. A key finding in this study is that the centripetal CBAXL decreases significantly after cataract surgery. These findings are in agreement with previous studies done by Koeppl et a ${ }^{10}$ and Park et al. ${ }^{12}$ The accommodative shortening of the centripetal axial length of

Table I The ultrasound biomicroscopy measurement of the angle configuration of the eyes with and without pilocarpine instillation before and after cataract surgery

\begin{tabular}{|c|c|c|c|c|c|c|}
\hline \multirow[t]{2}{*}{ Parameter } & \multicolumn{2}{|l|}{ Preoperative } & \multirow[t]{2}{*}{$P$-value } & \multicolumn{2}{|l|}{ Postoperative } & \multirow[t]{2}{*}{$P$-value } \\
\hline & Pilocarpine - & Pilocarpine + & & Pilocarpine - & Pilocarpine + & \\
\hline$A C D$ & $3.533 \mathrm{~mm}$ & $2.968 \mathrm{~mm}$ & $<0.5$ & $3.870 \mathrm{~mm}$ & $3.690 \mathrm{~mm}$ & $<0.5$ \\
\hline CBAXL & $1.699 \mathrm{~mm}$ & $1.685 \mathrm{~mm}$ & 0.2 & $1.898 \mathrm{~mm}$ & $1.668 \mathrm{~mm}$ & $<0.5$ \\
\hline SCPA & 40.11 & 39.50 & 0.3 & 41.95 & 36.67 & $<0.5$ \\
\hline
\end{tabular}

Abbreviations: ACD, anterior chamber depth; CBAXL, ciliary body axial length; SCPA, scleral ciliary process angle; pilocarpine $(-)$, before pilocarpine; pilocarpine $(+)$, after pilocarpine. 

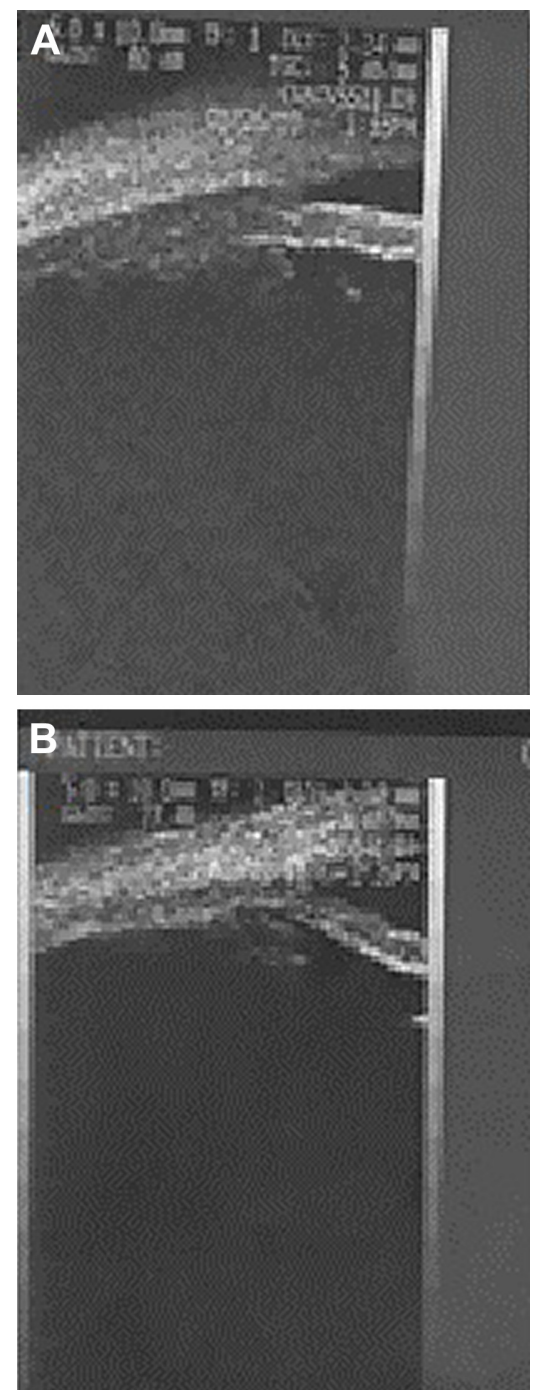

Figure 4 The $C B$ appearance postoperative (after cataract surgery) before (A) and after (B) pilocarpine.

Abbreviation: $\mathrm{CB}$, ciliary body.

the ciliary muscle $(P \leq 0.5)$ observed in this study supports the premise that suggests that cataract extraction results in a decrease in lens thickness, which leads to the improvement of ciliary body movement. This study reports a distinct decrease in accommodative SCPA after cataract extraction. These changes were reported by Kim et al ${ }^{13}$ and Park et al. ${ }^{12}$ The observed changes can be explained by iris posterior displacement that altered the ciliary body shape.

After cataract surgery, the pilocarpine induced decrease $(-0.180 \mathrm{~mm})$ in the ACD that was in agreement with Koeppl et al. ${ }^{10}$

\section{Conclusion}

The absolute and percentage variation between active and relaxed accommodation including inward shift of human
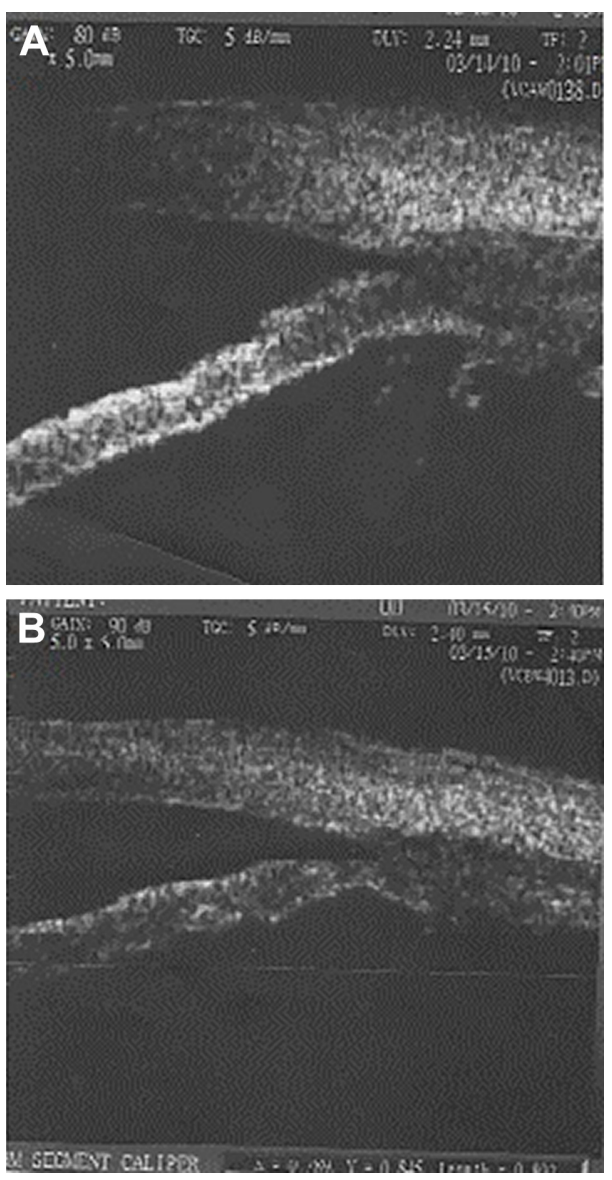

Figure 5 Difference of CBAXL postoperative, before $(\mathbf{A})$ and after (B) pilocarpine. Abbreviation: CBAXL, ciliary body axial length.

ciliary muscle mass during accommodation and optic movement forward supports the premise of the recovery of ciliary body contractility after cataract surgery.

\section{Disclosure}

The author reports no conflicts of interest in this work.

\section{References}

1. Pavlin CJ, Harasiewicz K, Sherar MD, Foster FS. Clinical use of UBM. Ophthalmology. 1991;98(3):287-295.

2. Rohen JW. Scanning electron microscopic studies of the zonular apparatus in human and monkey eyes. Invest Ophthalmol Vis Sci. 1979; 18(2):133-144.

3. Karwatowski WS, Weinreb RN. Imaging of cyclodialysis left by ultrasound biomicroscope. Am J Ophthalmol. 1994;117:514- 543.

4. Charman WN. The eye in focus: accommodation and presbyopia. Clin Exp Optom. 2008;91(3):207-225.

5. Ehrmann K, Ho A, Parel JM. Biomechanical analysis of the accommodative apparatus in primates. Clin Exp Optom. 2008;91(3):302-312.

6. Kaufman PL.Adler's. Physiology of the Eye: Clinical Application. 9th ed. Mosby, MO: St Louis; 1992:391-411.

7. Tamm ER, Lutjen-Drecoll E. Ciliary body. Microsc Res Tech. 1996; 33(5):390-439.

8. Ma J, Chen X. [Dynamic changes of configuration and position of human ciliary body during accommodation]. Zhonghua Yan Ke Za Zhi. 2004;40(9):590-596. Chinese. 
9. Pavlin CJ, Harasiewicz K, Foster FS. UBM of anterior segment structures in normal and glaucomatous eye. Am J Ophthalmol. 1992;113(4): 381-389.

10. Koeppl C, Findl O, Kriechbaum K, Dresler W. Comparisons of pilocarpine-induced and stimulus driven accommodation in phakic eye. Exp Eye Res. 2005;80(6):795-800.

11. Tello C, Liebmann J, Postash SD, Cohen H, Ritch R. Measurement of ultrasound biomicroscopy images: intraobserver and inter observer reliability. Invest Ophthalmol Vis Sci. 1994;35(9):3549-3552.
12. Park KA, Yun JH, Kee C. The effect of cataract extraction on the contractility of ciliary muscle. Am J Ophthalmology. 2008;146(1): $8-14$.

13. Kim M, Park KH, Kim TW, Kim DM. Changes in anterior chamber configuration after cataract surgery as measured by anterior segment optical coherence tomography. Korean J Ophthalmol. 2011;25(2):77-83.

\section{Publish your work in this journal}

Clinical Ophthalmology is an international, peer-reviewed journal covering all subspecialties within ophthalmology. Key topics include: Optometry; Visual science; Pharmacology and drug therapy in eye diseases; Basic Sciences; Primary and Secondary eye care; Patient Safety and Quality of Care Improvements. This journal is indexed on

Submit your manuscript here: http://www.dovepress.com/clinical-ophthalmology-journal

\section{Dovepress}

PubMed Central and CAS, and is the official journal of The Society of Clinical Ophthalmology (SCO). The manuscript management system is completely online and includes a very quick and fair peer-review system, which is all easy to use. Visit http://www.dovepress.com/ testimonials.php to read real quotes from published authors. 